\title{
Optimal Voltage Stability Improvement under Contingencies using Flower Pollination Algorithm and Thyristor Controlled Series Capacitor
}

\author{
Zulkiffli Abdul Hamid, Ismail Musirin, Muhammad Amirul Adli Nan, Zulkifli Othman \\ Faculty of Electrical Engineering, Universiti Teknologi MARA, 40450, Shah Alam, Selangor, Malaysia
}

\begin{tabular}{l}
\hline Article Info \\
\hline Article history: \\
Received May 22, 2018 \\
Revised Jul 21, 2018 \\
Accepted Aug 5, 2018 \\
\hline Keywords: \\
FACTS devices \\
Flower pollination algorithm \\
(FPA) \\
Optimization \\
Thyristor controlled series \\
capacitor (TCSC \\
Voltage stability \\
\hline
\end{tabular}

\begin{abstract}
Recent power systems necessitate for maintaining a safe voltage stability as the number of problems such as contingencies and reactive power insufficiency are increasing. In this paper, installation and sizing of Flexible Alternating Current Transmission System (FACTS) devices have been introduced for solving the voltage stability problems under contingencies. The FACTS device to be used is Thyristor Controlled Series Capacitor (TCSC). Besides improving the voltage magnitude at all buses to a desired level, installation of TCSC at proper locations can minimize total transmission losses of the system. To conduct the sizing task, the newly developed Flower Pollination Algorithm (FPA) has been implemented as the engine for optimization. Through experimentation, the results proved that the proposed placement and sizing technique has successfully mitigated the voltage stability problems. In addition, the computation time for FPA's convergence was tolerable with optimum results.
\end{abstract}

Copyright $\odot 2018$ Institute of Advanced Engineering and Science. All rights reserved.

Corresponding Author:

Zulkiffli Abdul Hamid, Ismail Musirin,

Faculty of Electrical Engineering,

Universiti Teknologi MARA,

40450, Shah Alam, Selangor, Malaysia.

Email: zulkiff19947@salam.uitm.edu.my

\section{INTRODUCTION}

The growing demand for electricity has made the utilities around the world as critical entity in energy market. To provide satisfactory services for consumers, a sophisticated scheme for maintaining voltage stability at a proper level is required. Voltage stability problem, especially voltage collapse, becomes a major issue due to the blackouts experienced by many countries for the past few years [1]. The term voltage stability is always referred to the ability of power system to maintain acceptable voltages as the system is subjected to a disturbance that may cause insufficiency of reactive power. Contingencies and failures of equipment are the types of disturbances occurred in power system which may lead to voltage instability [2]. Due to such problem, the power system may undergo the most serious malfunction: voltage collapse.

Theoretically, insufficient reactive power support is the major cause for voltage instability where the voltage drop is uncontrollable [3]. There are variety of methods to mitigate the voltage instability problems and one of them is through the use of Flexible Alternating Current Transmission System (FACTS) devices. The Unified Power Flow Controller (UPFC), one of the FACTS devices, is effective as it can maintain reactive power requirement of the system in the event of large disturbance and faults [4]. Besides that, Thyristor Controlled Series Capacitor (TCSC) can be suitable device for improving and increasing the network power transfer capability [5]. Thus, it is understood that the FACTS devices improve the stability by controlling the level of reactive power in the system, which means through the injection and absorption of reactive power [6]-[7]. 
To have a good installation of FACTS devices, proper placement (location for installation) and sizing (rating determination) should be conducted systematically as they promise the optimum improvement of voltage profiles and losses minimization [8]-[9]. While placement can be done through analytical methods such as sensitivity analysis and bus ranking, sizing is frequently conducted through optimization. The socalled 'trial and error' approach is rarely used when determining the size of FACTS devices as it does not offer optimal solution. It was said that proper selection of placement location can lead to efficient line flow control and maintain bus voltages at acceptable levels, thus enhancing the voltage dependability edges [10]. Implementing optimization approach necessitates for meta-heuristic algorithms like Genetic Algorithm (GA), Particle Sawrm Optimization (PSO), Ant Colony Optmization (ACO), Bacterial Foraging Algorithm (BFA) and the latest one Flower Pollination Algorithm (FPA).

This paper proposes a method for optimal voltage stability improvement through TCSC and Flower Pollination Algorithm (FPA) considering contingency situations such as line outages. The study includes various comparative studies on the methods of TCSC placement as well as its effect on voltage profiles and transmission losses under various contingencies. Performance of FPA in the case study shall be assessed afterwards in terms of computation time for convergence and solution optimality. Lastly, all significant findings and analysis will be concluded in the last section of this paper.

\section{RESEARCH METHOD}

In this section, the fundamental of TCSC operation and proposed FPA algorithm are briefly explained.

\subsection{TCSC in Power System}

TCSC is a FACTS device installed in series with the transmission line of power system. Technically, TCSC consists of a series capacitor bank shunted by Thyristor Controlled Reactor (TCR). Such a connection provides a smooth variable series capacitive reactance, i.e. the control action taken on the reactance will give a corresponding reactive power compensation (either injection or absorption). The advantages of using TCSC in power system are voltage stability improvement, effective power flow control and damping power oscillations. Figure 1 shows the schematic diagram for TCSC connected along a transmission line. The whole circuitry which comprises of capacitor, inductor and two thyristors represents the basic TCSC circuit as in Figure 1 [11]. Hence, the combination of both capacitive and inductive reactance represents the TCSC's equivalent reactance, $X_{T C S C}$.

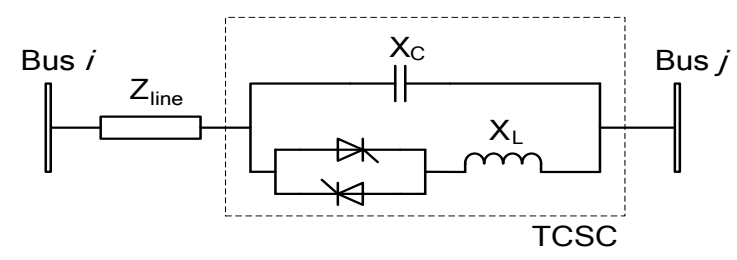

Figure 1. Schematic diagram for TCSC

In this paper, the range of TCSC reactance to be used is between -0.7 p.u. and 0.2 p.u. Thus, the developed FPA will search the best TCSC sizes between the range while ensuring no constraint violation during optimization. The algebraic summation between the line impedance and TCSC reactance will result in power flow control along the line, hence producing the desired compensation of reactive power. This control action will give a corresponding improvement on the bus voltages as well as losses reduction. Prior to that, however, the placement of TCSC will be conducted through the Maximum Loadability Identification (MLI) technique in which the sensitive lines may be identified.

\subsection{Proposed Algorithm for FPA}

Yang in [12] for the first time proposed an algorithm that mimics the pollination of flowers, known as the Flower Pollination Algorithm (FPA). The biological process of pollination involves pollinators, sometimes called as pollen-carrying agent, for spreading the pollens. Insects can be the example of pollinators. Basically, the FPA consists of two significant processes namely local and global pollination. Global pollination refers to biotic and cross-pollination whereby the pollinators travel in a path that obeys Levy flight. This means that the process necessitates for pollinators travelling at a long distance. On the other 
hand, local pollination refers to abiotic and self-pollination. This process occurs when the pollen of the same flower fertilizes to be another flower. Usually, no pollinators such as insects involved in this process. The proposed problem formulation for this study is presented as follows:

$$
f\left(X_{i}^{t}\right)=\max \left\{V_{k}\right\}
$$

Where:

$$
X_{i}^{t}=\left[X_{T C S C}^{1}, X_{T C S C}^{2}, \ldots X_{T C S C}^{n} \ldots X_{T C S C}^{N}\right]
$$

Subject to:

$$
\begin{aligned}
& -0.7 \text { p.u. } \leq X_{\text {TCSC }} \leq 0.2 \text { p.u. } \\
& \sum P_{G}=\sum P_{D}+P_{\text {loss }} \\
& \text { FVSI } I_{\text {max }} \leq 0.9
\end{aligned}
$$

Where, $X_{i}^{t}$ is $i$-th solution (i.e. the pollen) at $t$-th iteration, $X_{T C S C}$ is the TCSC reactance, $N$ is the number of TCSC to be installed, $P_{G}$ is the generator power, $P_{D}$ is the total demand, $P_{\text {loss }}$ is the total losses, $F V S I_{\text {max }}$ is a stability index poposed by Musirin [13] for constraint violation check, $f\left(X_{i}^{t}\right)$ is the fitness to be optimized and $V_{k}$ is the voltage magnitude at $k$-th bus. Hence, the objective function for FPA is to optimize the voltage profile at all buses. The proposed FPA algorithm in the context of the case study is presented as follows.

\section{Step 1: initialization}

At first, initialization of parameters is done by specifiying the values for FPA's parameters heuristically. Next, a group of initial solutions, known as population, is generated randomly while satisfying all the constraints as in (3), (4) and (5).

\section{Step 2: fitness evaluation}

Later, all the randomly generated solutions are evaluated through load flow analysis. The aim is to improve the voltage magnitude at all buses as indicated in (1).

\section{Step 3: generate new pollens}

This is the step where the algorithm will decide either to use global or local pollination process in generating the new group of pollens, i.e. $X_{i}^{t+1}$. First, in global pollination, flower pollen gametes are carried by pollinators such as insect, and pollen can travel over a long distance because insects can often fly and move in a much longer range. Therefore, it can be represented mathematically as:

$$
X_{i}^{t+1}=X_{i}^{t}+\gamma L(\lambda)\left(g^{*}-X_{i}^{t}\right)
$$

Where, $g^{*}$ is the current best solution found among all solutions at the current iteration. Here, $\gamma$ is a scaling factor to control step size. The scaling factor, $\gamma$ is set to 0.01 . In addition, $L(\lambda)$ is the parameter that corresponds to the strength of pollination, which essentially is also the step size (i.e. $s$ ) with $\lambda$ is set to $1 \times 10^{-}$ 6 . Since insects may move over a long distance with various distance steps, we can use Levy flight to imitate this characteristic efficiently; that is, to draw $L(\lambda)>0$ from a Levy distribution. This is given as follows:

$$
L(\lambda)=\frac{\lambda \Gamma(\lambda) \sin \left(\frac{\Pi \lambda}{2}\right)}{\Pi} \cdot \frac{1}{s^{1+\lambda}} \quad ; \quad s \gg s_{o} \gg 0
$$

Where, $\Gamma(\lambda)$ is the standard gamma function and this distribution is valid for large step size, $s>0$. On the other hand, the local pollination is represented by the following equation:

$$
X_{i}^{t+1}=X_{i}^{t}+\varepsilon\left(X_{j}^{t}-X_{i}^{t}\right)
$$

Where, $X_{j}^{t}$ is pollen from different flower of the same plant species (i.e. random solution) and $\varepsilon$ is a random number drawn from a uniform distribution between $[0,1]$.

Step 4: updating the population

After the new pollens have been generated, they will be evaluated through step 2. Next, both the current and new population will be combined, sorted and discarded to maintain the original size of population.

Optimal Voltage Stability Improvement under Contingencies using Flower... (Zulkiffli Abdul Hamid) 


\section{Step 5: termination}

The convergence of the algorithm will be achived if all solutions have approximately equal fitness. Then, the optimization is terminated. Otherwise, step 2 to 5 will be repeated. The overall algorithm for FPA is shown in Figure 2.

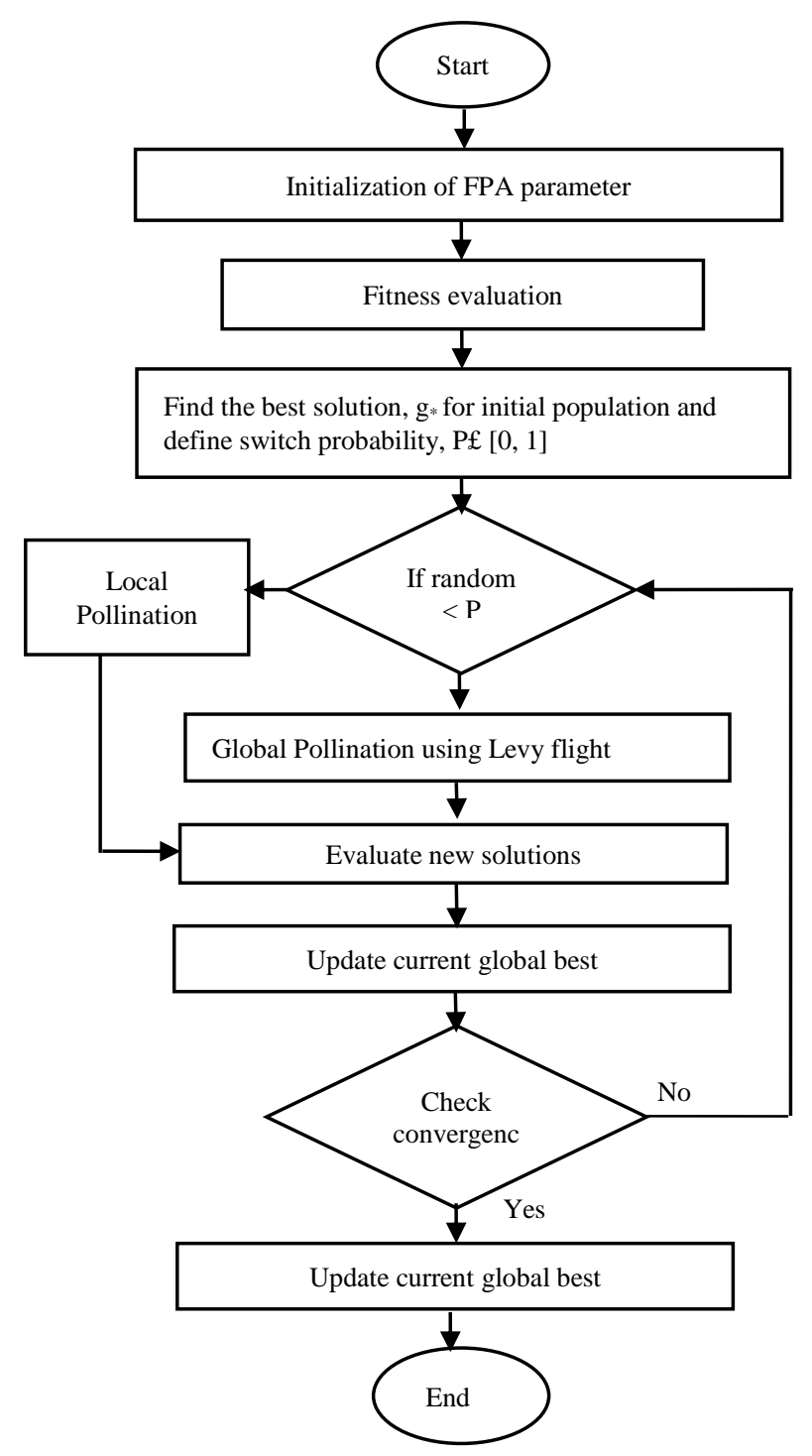

Figure 2. FPA's overall algorithm

\section{RESULTS AND ANALYSIS}

There are three case studies focused here: (1) comparison between single and multiple installation of TCSC, (2) comparison between different methods of TCSC placement and (3) FPA performance. In this paper, four types of contingencies (or line outage) were specified and their notations are used as C1, C2, C3 and $\mathrm{C} 4$ to indicate their increasing severity. The IEEE 30-bus reliability test system (RTS) was used as the test system throughout this paper.

\subsection{Comparison between single and multiple installation of TCSC under Contingencies}

In this section, the effects of single and multiple installation of TCSC in power system are assessed based on minimum voltage magnitude and total losses at post optimization. The results are tabulated in Table 1 and the graphs as in Figure 3 and 4 were plotted based on the table. 
Table 1. Improvement of voltage and total losses - single \& multiple TCSC installation

\begin{tabular}{|c|c|c|c|c|c|c|c|c|c|}
\hline $\begin{array}{l}\text { System } \\
\text { state }\end{array}$ & $\begin{array}{l}\text { Outage } \\
\text { number }\end{array}$ & \multicolumn{2}{|c|}{ Before installation } & \multicolumn{2}{|c|}{ Single installation } & \multicolumn{4}{|c|}{ Multiple installation } \\
\hline $\mathrm{C} 1$ & 1 line & 0.8984 & 64.041 & 8 & 0.960 & 42.532 & $6,8,10,17$ & 0.980 & 27.845 \\
\hline $\mathrm{C} 2$ & 2 lines & 0.8668 & 66.196 & 8 & 0.950 & 52.535 & $6,8,10,17$ & 0.960 & 60.107 \\
\hline $\mathrm{C} 3$ & 3 lines & 0.8571 & 82.286 & 8 & 0.980 & 59.905 & $6,8,10,17$ & 1.000 & 25.973 \\
\hline
\end{tabular}

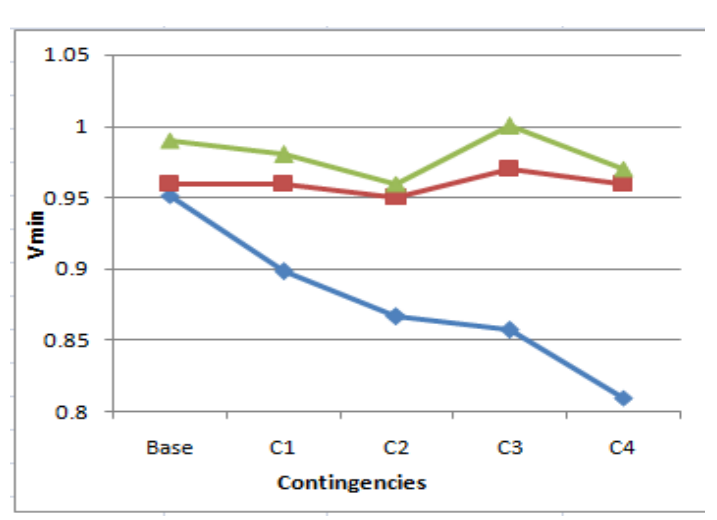

Figure 3. Minimum voltage (in p.u.) for single and multiple installation of TCSC

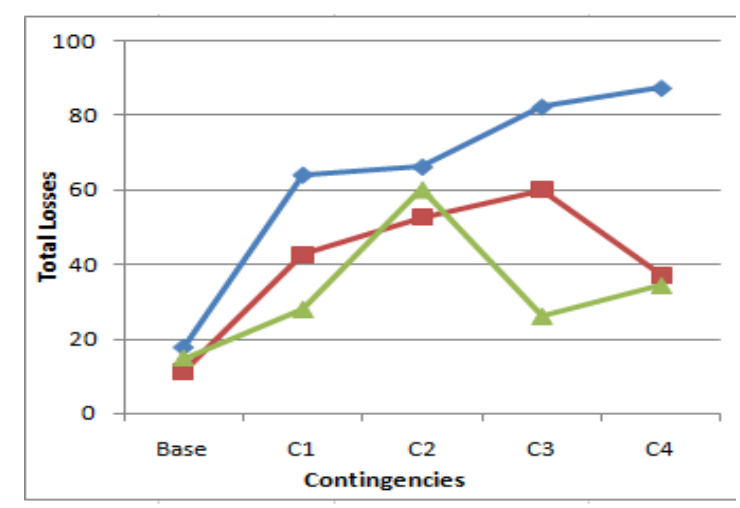

Figure 4. Total losses (in MW) for single and multiple installation of TCSC

Based on Figure 3 and 4, with no TCSC installed to the system, the voltage reduces while the total losses increase as the contingency severity increases, that is, when the number of outage lines increases. The improvement on voltage profiles by single and multiple installation of TCSC is reasonable as the magnitudes are between 0.95 p.u. and 1.05 p.u. This can be seen in Figure 3. Through all contingencies, single installation promises an improvement to both voltage and total losses, but the multiple installation offers better results. For example, in Figure 4 the losses reduced by single installation at C3 is 59.905 MW, which is equivalent to 27 percent of reduction. A further reduction in losses is obtained when multiple installation is implemented, which is $25.973 \mathrm{MW}$ or equivalent to 68 percent of losses reduction. It is not to say that multiple installation is the most recommended scheme, but if the cost of installation is not the issue, then it could be a favourable method among utilities or service providers.

\subsection{Comparison between Random and MLI-based Placement of TCSC}

Next, this section analyses the effects of two different methods of TCSC placement. The first method is by installing the TCSC at random locations in power systems, hence it is called as random placement. The second one selects the suitable locations based on a rank produced from a method called Maximum Loadability Identification (MLI), thus it is known as MLI-based placement. Article [14] explains the concept of MLI in the field of voltage stability assessment. The results are tabulated in Table 2 and the graphs as in Figure 5 and 6 were plotted based on the table. There is only a small improvement resulted from random placement as can be seen in Figure 5. At all levels of contingencies, the voltage magnitude is below 0.95 p.u. This shows that inappropriate selection of TCSC locations does not promise any improvement to the system.

Table 2. Improvement of Voltage and Total Losses - random and MLI-based Placement

\begin{tabular}{|c|c|c|c|c|c|c|c|c|c|}
\hline \multirow[b]{2}{*}{$\begin{array}{l}\text { System } \\
\text { state }\end{array}$} & \multirow[b]{2}{*}{$\begin{array}{l}\text { Outage } \\
\text { number }\end{array}$} & \multicolumn{2}{|c|}{ Before installation } & \multicolumn{3}{|c|}{ Random placement } & \multicolumn{3}{|c|}{ MLI-based placement } \\
\hline & & $\begin{array}{l}\text { Voltage } \\
\text { (p.u.) }\end{array}$ & $\begin{array}{l}\text { Losses } \\
\text { (MW) }\end{array}$ & $\begin{array}{l}\text { Installed } \\
\text { line }\end{array}$ & $\begin{array}{l}\text { Voltage } \\
\text { (p.u.) }\end{array}$ & $\begin{array}{l}\text { Losses } \\
\text { (MW) }\end{array}$ & $\begin{array}{l}\text { Installed } \\
\text { line }\end{array}$ & $\begin{array}{c}\text { Voltage } \\
\text { (p.u.) }\end{array}$ & $\begin{array}{l}\text { Losses } \\
\text { (MW) }\end{array}$ \\
\hline $\mathrm{C} 1$ & 1 line & 0.8984 & 64.041 & 6 & 0.910 & 63.801 & 13 & 0.960 & 62.313 \\
\hline $\mathrm{C} 2$ & 2 lines & 0.8668 & 66.196 & 16 & 0.870 & 66.198 & 8 & 0.950 & 53.535 \\
\hline C3 & 3 lines & 0.8571 & 82.286 & 10 & 0.880 & 81.766 & 12 & 0.960 & 30.527 \\
\hline
\end{tabular}




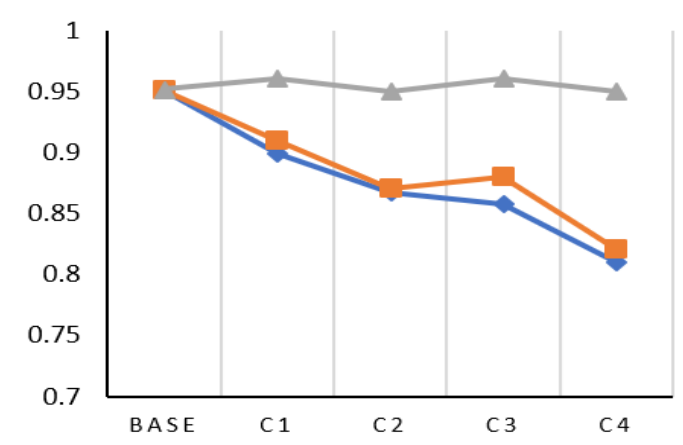

Figure 5. Minimum voltage (in p.u.) for random and MLI-based placement of TCSC

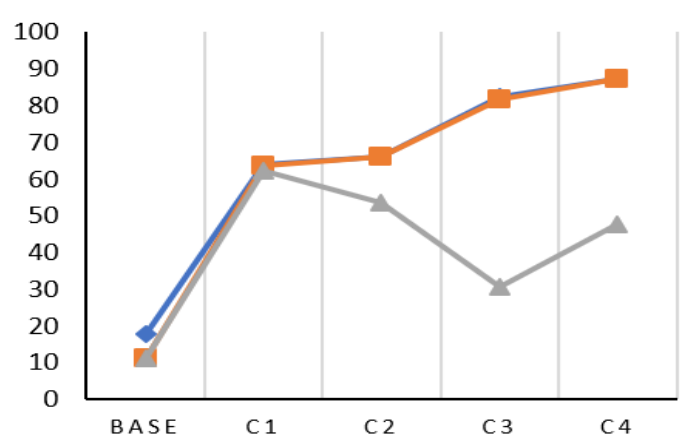

Figure 6. Total losses (in MW) for random and MLIbased placement of TCSC

The MLI-based placement, on the other hand, has successfully maintained the voltage magnitude at least 0.95 p.u. at all levels of contingencies. Obviously, this method is consistent in promising an improvement to the system compared to random placement. The same goes to the losses whereby the random placement has failed to yield any obvious reduction. In contrast, the MLI results in effective minimization of losses especially at contingency C2, C3 and C4. The percentages of reduction at the three contingency levels are 19 percent, 63 percent and 45 percent respectively. Thus, it can be said that installation of TCSC necessitates for a proper method of placement in producing a better improvement to the system.

\subsection{FPA performance}

This section presents the analysis of FPA performance with regards to the two previous case studies. The parameter of FPA concerned here is the switch probability $P_{o}$, which is used to control the preference of the algorithm, either global or local pollination, in producing new solutions. Two values were chosen intuitively to see the effect of the parameter on FPA performance, which are 0.5 and 0.8 . The results are tabulated in Table 3 and the graphs as in Figure 7, 8 and 9 were plotted based on the table. Firstly, there is no obvious difference in voltage magnitude resulted from $P_{o}=0.5$ and $P_{o}=0.8$ as can be seen in Figure 7.

Table 3. Effect of FPA's switch Probability on Optimization Performance

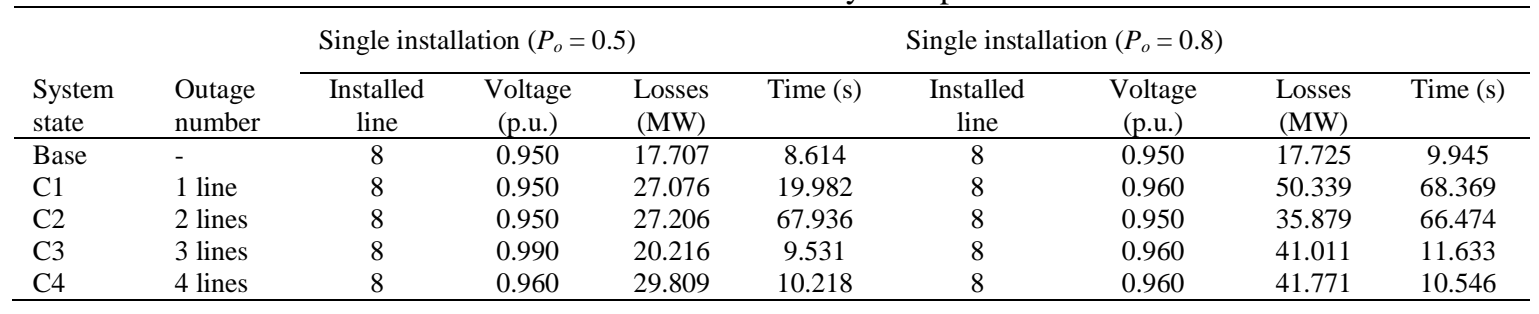

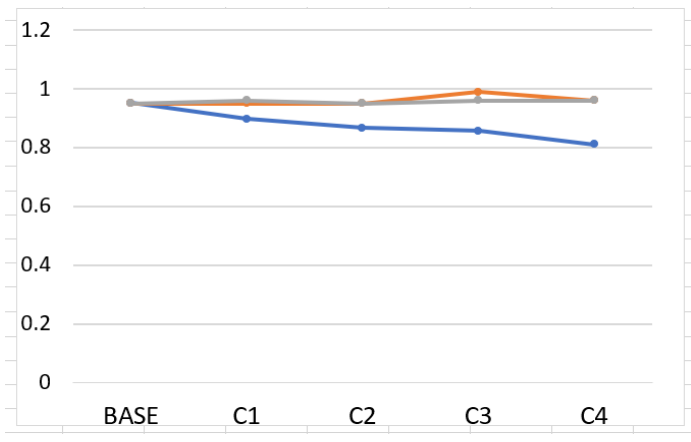

Figure 7. Minimum voltage (in p.u.) for $\mathrm{P}_{\mathrm{o}}=0.5$ and $\mathrm{P}_{\mathrm{o}}=0.8-$ single installation

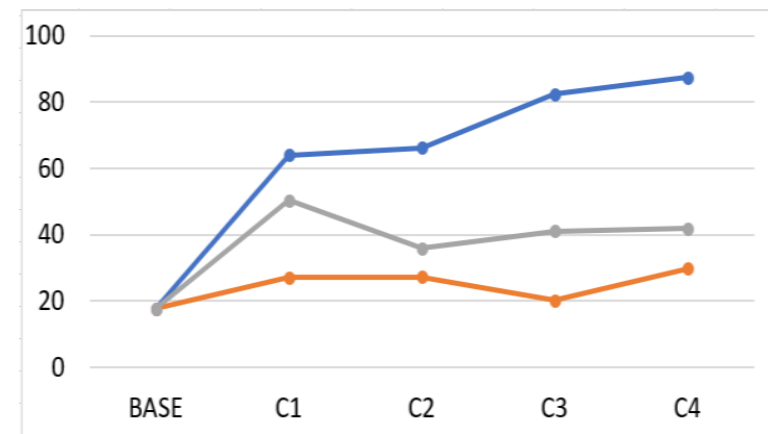

Figure 8. Total losses (in MW) for for $\mathrm{P}_{\mathrm{o}}=0.5$ and $\mathrm{P}_{\mathrm{o}}$ $=0.8-$ single installation 


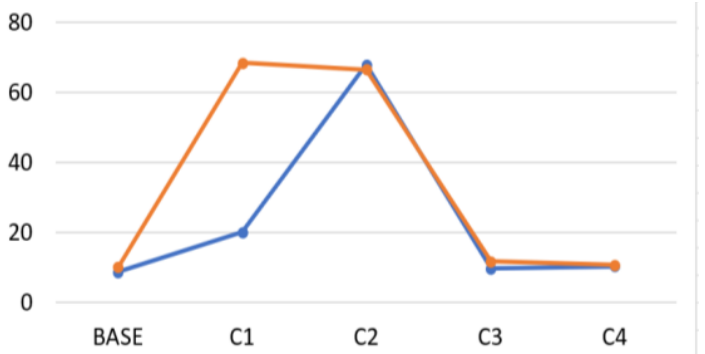

Figure 9. FPA's computation time (in seconds) for $\mathrm{P}_{\mathrm{o}}=0.5$ and $\mathrm{P}_{\mathrm{o}}=0.8$

The voltage magnitude for both values of $\mathrm{P}_{\mathrm{o}}$ is above 0.95 p.u. at all contingencies. However, this is different for losses minimization whereby the FPA did better if $P_{o}=0.5$. From Figure 8, the FPA with $P_{o}=$ 0.5 was able to reduce more losses than that of $P_{o}=0.8$, and this is true for all levels of contingencies. Despite the voltage and losses at post-optimization, the required computation is another issue. A good optimization shall produce optimal solution with minimum computation time. Based on Figure 9, it is not to say that smaller $P_{o}$ is better than the larger one since both values required very close computation time, except for contingency $\mathrm{C} 1$. This signifies that the switch probability $P_{o}$, perhaps, has nothing to do with the speed of algorithm. It does affect the optimality of solution, but not the computation time.

\section{CONCLUSION}

In this paper, the optimization algorithm known as FPA has been developed for solving power system problem. The FPA was used to perform optimal sizing of TCSC for losses minimization and voltage magnitude improvement. The analysis of the results justified the ability of FPA in producing satisfactory voltage stability improvement at various conditions of system, including contingencies. Therefore, it is no doubt to conclude that the aims of this paper are successfully achieved. For future recommendation, the FPA can be hybridized with other meta-heuristic techniques to increase its performance in terms of convergence speed and optimality of solution.

\section{ACKNOWLEDGEMENTS}

The authors would like to acknowledge the Institute of Research Management and Innovation (IRMI) UiTM Shah Alam, Selangor, Malaysia for the financial support of this research. This research is supported by IRMI under the LESTARI Research Grant Scheme with project code: 600-IRMI/MyRA 5/3/LESTARI (0024/2016).

\section{REFERENCES}

[1] Y. K. Wu, S. M. Chang, Y. L. Hu, "Literature Review of Power System Blackouts", Energy Procedia, Vol. 141, December 2017, pp. 428-431.

[2] S. D. Naik, M. K. Khedkar, S. S. Bhat, "Effect of line contingency on static voltage stability and maximum loadability in large multi bus power system", International Journal of Electrical Power \& Energy Systems, Vol. 67, May 2015, pp. 448-452.

[3] A. Mohanty, M. Viswavandya, S. Mohanty, P. K. Ray, S. Patra, "Modelling, simulation and optimisation of robust PV based micro grid for mitigation of reactive power and voltage instability", International Journal of Electrical Power \& Energy Systems, Vol. 81, October 2016, pp. 444-458.

[4] S. Dutta, P. Mukhopadhyay, P. K. Roy, D. Nanti, "Unified power flow controller based reactive power dispatch using oppositional krill herd algorithm”, International Journal of Electrical Power \& Energy Systems Vol. 80, September 2016, pp. 10-25.

[5] R. Agrawal, S. K. Bharadwaj, D. P. Kothari, "Population based evolutionary optimization techniques for optimal allocation and sizing of Thyristor Controlled Series Capacitor", Journal of Electrical Systems and Information Technology, Available online 7 February 2018.

[6] H. B. Nagesh and P. S. Puttaswamy, "Enhancement of Voltage Stability Margin Using FACTS Controllers," Internation Journal of Computer and Electrical Engineering, Vol. 5, no. 2, pp. 261-265, 2013.

[7] S. Raj, B. Bhattacharyya, "Optimal placement of TCSC and SVC for reactive power planning using Whale optimization algorithm”, Swarm and Evolutionary Computation, Available online 23 December 2017.

[8] A. Sode-Yome, N. Mithulananthan, K. Y. Lee, "Static voltage stability margin enhancement using STATCOM, TCSC and SSSC," Proc. IEEE Power Eng. Soc. Transm. Distrib. Conf., vol. 2005, no. October 2016, pp. 1-6, 2005. 
[9] C. T. V. Kumar and P. B. Reddy, "Comparison of FACTS Devices to Reduce Power System Losses and Improvement in Voltage Stability by Using Optimization Technique," International Journal of Science and Research (IJSR), vol. 4, no. 10, pp. 2246-2250, 2015.

[10] C. Rambabu, D. Y. P. Obulesu, and D. C. Saibabu, "Improvement of Voltage Profile and Reduce Power System Losses by using Multi Type Facts Devices," International Journal of Computer Applications, vol. 13, no. 2, pp. 37 41, 2011.

[11] D. K. Sahoo, R. K. Sahu, G. T. C. Sekhar, S. Panda, "A novel modified differential evolution algorithm optimized fuzzy proportional integral derivative controller for load frequency control with thyristor controlled series compensator", Journal of Electrical Systems and Information Technology, Available online 28 December 2016.

[12] X. S. Yang, M. Karamanoglu, X. He, Multi-objective Flower Algorithm for Optimization, Procedia Computer Science, Vol. 18, 2013, Pages 861-868.

[13] I. Musirin, T. K. A. Rahman, "Evolutionary programming optimization technique for solving reactive power planning power system," WSEAS Transactions on Information Science and Applications, vol. 2, no. 5, pp. 495 - 500, 2005.

[14] P. Acharjee, "Identification of maximum loadability limit and weak buses using security constraint genetic algorithm”, International Journal of Electrical Power \& Energy Systems, Vol. 36, Issue 1, March 2012, pp. 40-50. 